Pak. j. sci. ind. res. Ser. A: phys. sci. 201255 (2) 92-97

\title{
Measurement of Noise Intensity in Tangail Municipal Area, Bangladesh
}

\author{
Md. Younus Mia*, Md. Uzzal Hossain and Shazia Farzana \\ Department of Environmental Science and Resource Management, Mawlana Bhashani Science and Technology \\ University, Santosh, Tangail-1902, Bangladesh
}

(received January 1, 2011; revised May 28, 2011; accepted June 7, 2011)

\begin{abstract}
The study reports community noise levels measured during day time in fast developing semiurban areas of Tangail Municipal Area (TMA), Bangladesh. The noise levels were measured following standard procedure using calibrated sound pressure level meter at many places predominated by commercial, sensitive and residential tenements at Tangail Municipal Areas. The result of the study revealed that the noise intensity surpassed to the prescribed levels in the study area. The study also finds that overall minimum and maximum noise levels for the main road are 57.0 and $112.3 \mathrm{~dB}(\mathrm{~A})$, for new and old bus stand are 57.6 and $105.4 \mathrm{~dB}(\mathrm{~A})$, for residential tenements (Thana para) are 57.1 and $103.3 \mathrm{~dB}(\mathrm{~A})$, for commercial area (Nirala mur) are 62.3 and $101.3 \mathrm{~dB}(\mathrm{~A})$ and Babi stand 66.5 and $112.3 \mathrm{~dB}(\mathrm{~A})$, for sensitive area (General Hospital) are 57.0 and $99.9 \mathrm{~dB}$ (A) and educational institution area (Mahmudul Hasan College) are 57.7 and $104.6 \mathrm{~dB}(\mathrm{~A})$, respectively. The minimum and maximum noise levels observed in the study area were 57.0 and $112.3 \mathrm{~dB}(\mathrm{~A})$, respectively. It is conspicuously proved that the noise pollution levels in TMA exceeded the recommended level by WHO at 34 of 47 measuring points.
\end{abstract}

Keywords: noise pollution, sound level, environment

\section{Introduction}

Excessive or unwanted sound, e.g. noise is a major and potential problem for the quality of life in urban areas which affects most of the exposed population lived in urban areas. Since it disrupts physiological and psychological condition such as; annoyance and aggression, hypertension, high stress levels, hearing loss, sleep disturbances, forgetfulness, severe depression and there is no medicine to cure hearing loss. Prevention to over exposure is the only alternative left, though the problem is increasing with parallely increasing urbanization and motorization. Frequent exposure to high level of noise hampers physical and mental peace and may cause damage to the health. Along with the increasing degree of air and water pollution, the inhabitants of Tangail city are being exposed to high level of noise pollution. Although there are many sources of noise which include motorized traffic like heavy and medium truck, tempo, car horns, bus, motocycle, $\mathrm{CNG}$, construction works and indiscriminate use of loud speakers, miking (noise created from public microphone for public function), public gathering, etc. are the principal sources of noise in Tangail Municipal Area. With the increase in the number of *Author for correspondence; E-mail: oshin1996@yahoo.com motorized vehicles in the city, the hazard of noise pollution has increased and exceeded the level of tolerance. It is well established that noise is a potential hazard to health, communication and enjoyment of social life. It is becoming an unjustifiable interference and imposition upon human comfort, health and quality of modern life (Ahmad, 1998). The hearing ability of the inhabitants of Dhaka, the capital city of Bangladesh has reduced during the last ten years. As a result about $5-7 \%$ of the patients admitted to the Bangabandhu Sheikh Mujibar Rahman Medical University, Dhaka for overcoming such problems. The city is suffering from permanent deafness due to noise pollution (Alam et al., 2001). Disturbances created by noise may cause hypertension, headache, indigestion, peptic ulcer, pharyngitis, atherosclerosis, bradycardia and ectopic beat, etc. (Kadiyali, 1997; OECD, 1995; Papacostas and Prevedouros, 1993). Above 120 decibel $(\mathrm{dB})$ the sound produces discomfort and even pain. Noise pollution is a significant environmental problem in many rapidly urbanizing areas. This problem is not properly recognized despite the fact that it is steadily growing in developing countries (Murthy et al., 2007).

It has been assumed that the inhabitants of TMA also affected by above mentioned problems. Keeping above 
points into consideration the study was conducted to measure the environmental noise levels and assess the noise pollution in the TMA predominantly due to traffic mobility. The study was conducted to compare the noise pollution levels at busy roads/road junctions, passengers loading parks, commercial, educational centre and residential areas and analyzing its level of severity in TMA.

\section{Materials and Methods}

Study area. Tangail is the fast growing urban area, situated 100 kilometers in the north of capital city Dhaka, along with Dhaka-Mymensingh Highway. It is one of the oldest District towns in Bangladesh which has been established in July $1^{\text {st }}$, 1887 . At present the area of the TMA is $29.43 \mathrm{~km}^{2}$ and total population is around 1,28,785 (BBS, 2001).

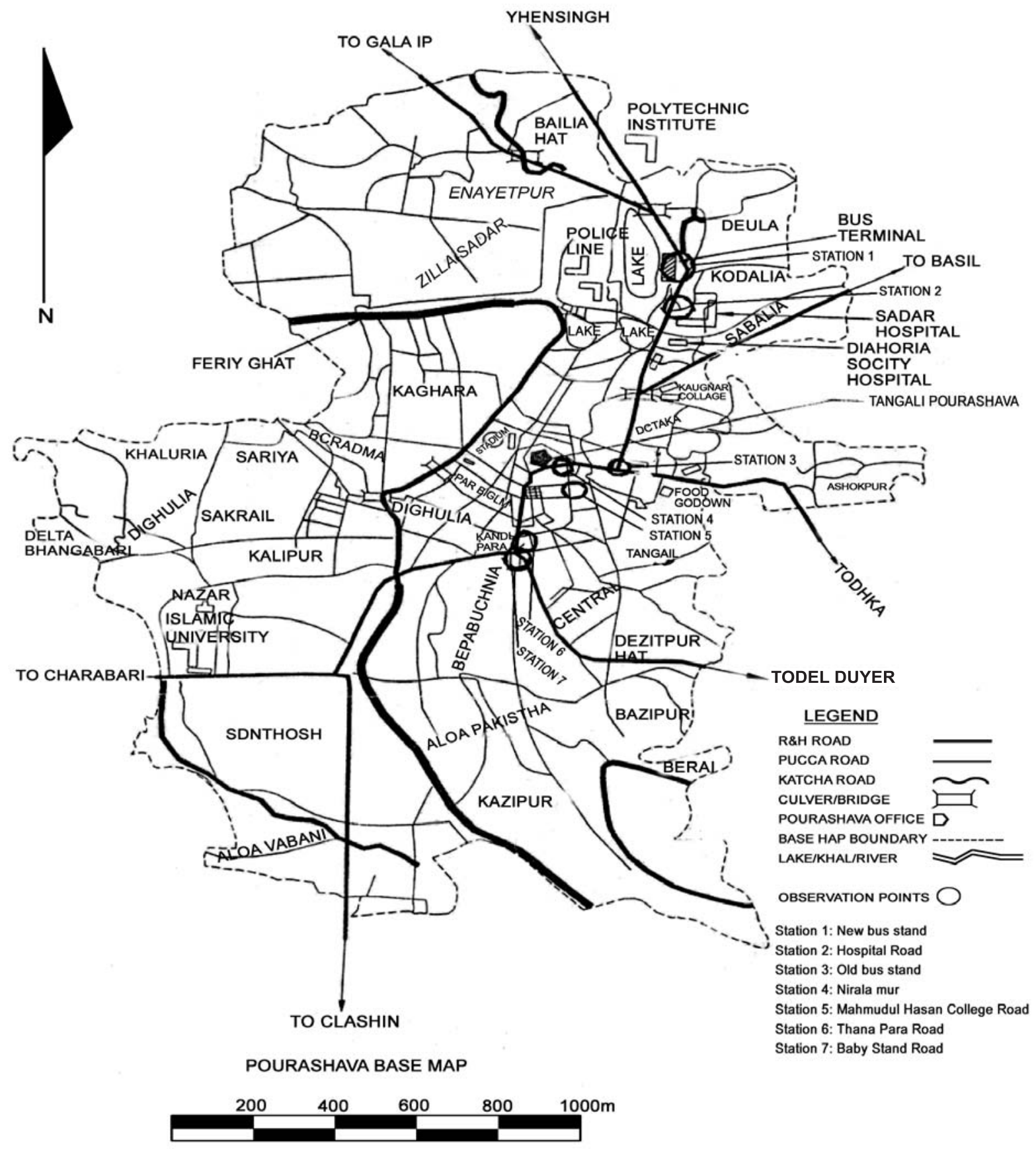

Fig. 1. Map showing Tangail Municipal Area with study areas. 
In this study, 4 IN 1 Multi-Function Environment Meter (STANDARD-ST-8820-Environment Meter, Japan) was used to measure the noise levels which consists of a microphone that converts the pattern of sound pressure fluctuation into a similar pattern of electric voltage, amplifiers and a voltage meter that is normally calibrated to read in decibel $(\mathrm{dB})$.

The study was conducted at seven locations as follow: 1. New bus stand (mixed area), 2. Hospital road (infront of Tangail General Hospital), 3. Old bus stand (mixed area), 4. Nirala mur (commercial area), 5. Thana para (residential area), 6. Mahmudul Hasan College (sensitive area) and 7. Babi stand (commercial area) in TMA. The intent of measuring the noise levels was firstly to have an estimate of its individual contribution to the environmental noise and secondly, to reflect the maintenance levels of the vehicles prevalent in the area. The combinations included heavy trucks and buses, medium including mini trucks and buses, automobiles like vehicles operated by compressed natural gas $(\mathrm{CNG})$, motorcycle, babi taxi and normal condition (e.g. non vehicle and only for human creating noise).

All the measurements were taken at different times during day time (between 10 am to $2 \mathrm{pm}$ ) from November 25 to December 05, 2010. For accuracy, values were collected thrice at each point then averaged through summation of all values divided by the number of observations. At the time of collecting data of noises, values of frequent peaks were measured. Then maximum peak was considered as maximum value and minimum peak considered as minimum value.

The minimum and maximum levels of sound were recorded in each observation from various types of vehicles. The duration of data collection in each spot was within one hour and in some cases more. Equivalent continuous sound pressure level, or $\mathrm{L}_{\text {eq }}$, is the constant noise level that would result in the same total sound energy being produced over a given period. $\mathrm{L}_{\text {eq }}$ can be described mathematically by the following equations:

$L_{\text {eq }}=10 \log _{10}\left(\frac{1}{T_{M}} \int_{Q}^{T M}\left(\frac{P(t)}{P_{0}}\right)^{2} d t\right)$

where:

- $\mathrm{L}_{\text {eq }}$ is the equivalent continuous linear weighted sound pressure level $20 \mu \mathrm{Pa}$, determined over a measured time interval $\mathrm{T}_{\mathrm{M}}$ (secs)
- $\mathrm{P}(\mathrm{t})$ is the instantaneous sound pressure of the sound signal

- $\mathrm{P}_{0}$ is the reference sound pressure of $20 \mu \mathrm{Pa}$

When the instantaneous A-weighted sound pressure $\left(\mathrm{P}_{\mathrm{A}}\right)$ of the sound signal is introduced the equivalent continuous A-weighted sound pressure level determined over time interval $\mathrm{T}_{\mathrm{M}}$ is as follows:

$L_{\text {eq }}=10 \log _{10}\left(\frac{1}{T_{M}} \int_{Q}^{\mathrm{TM}}\left(\frac{P_{A}(t)}{P_{0}}\right)^{2} d t\right) \ldots \ldots \ldots \ldots$.

In practice when measuring noise, it is possible to take $\mathrm{L}_{\mathrm{eq}}$ readings with instrument of short duration, i.e. $<5 \mathrm{~min}$, providing all variations of noise emissions are covered.

Finally, the data were arranged with the total number of observations, the minimum and maximum values of sound level and averaged for each type of vehicle in each spot.

\section{Results and Discussion}

The noise level was measured at seven locations in TMA. The minimum, maximum and averaged environmental noise levels in all spots are shown in Table 1. The minimum and maximum noise levels measured in the study area were $57.0 \mathrm{~dB}(\mathrm{~A})$ at hospital road (infront of hospital) and 112.3 $\mathrm{dB}$ (A) at Babi stand (commercial area), respectively. The source is predominantly attributable to motor vehicular traffic. The noise level minimum of 58.4 and $57.6 \mathrm{~dB}(\mathrm{~A})$ and maximum of 105.1 and $105.4 \mathrm{~dB}(\mathrm{~A})$ were measured, respectively at New bus stand and Old bus stand (Table 2 and 3 ). Among 772 trials in above mentioned 7 locations, the noise level has surpassed the permissible limit of 70 $\mathrm{dB}(\mathrm{A})$ in all locations. However, it would be noted that the level exceedance was during the day time. The departure from prescribed limit is substantial and with this level on a chronic measure of time can casue definitive health problems to the exposed population.

Our present results of noise level have exceeded the standard traffic noise limit of $70 \mathrm{~dB}$ (A) and noise level of $45 \mathrm{~dB}$ (A) prescribed by DoE (Department of Environment, Bangladesh). Comparison among the standard noise levels and the results obtained is shown in Table 4.

Interestingly, the Tangail General Hospital is located near the new bus stand, where, large numbers of human and heavy buses arrives and go out from this place 
Table 1. Traffic noise in TMA along the main and junction road

\begin{tabular}{|c|c|c|c|c|c|c|}
\hline \multirow[t]{2}{*}{ S. no. } & \multirow[t]{2}{*}{ Experimental locations } & \multirow[b]{2}{*}{$\mathrm{N}^{*}$} & \multicolumn{3}{|c|}{ Sound pressure levels, $\mathrm{dB}(\mathrm{A})$} & \multirow[t]{2}{*}{$\mathrm{L}_{\mathrm{eq}}(\mathrm{dB})$} \\
\hline & & & Min & Max & Average $(\mathrm{Sd} \pm)$ & \\
\hline 1 & New bus stand (mixed area) & 155 & 58.4 & 105.1 & $85.21( \pm 33.02)$ & 73.1 \\
\hline 2 & $\begin{array}{l}\text { Hospital road (infront of Tangail } \\
\text { General Hospital) }\end{array}$ & 135 & 57.0 & 99.9 & $84.07( \pm 30.34)$ & 67.0 \\
\hline 3 & Old bus stand (mixed area) & 124 & 57.6 & 105.4 & $87.71( \pm 33.79)$ & 70.3 \\
\hline 4 & Nirala mur (commercial area) & 87 & 62.3 & 101.3 & $81.68( \pm 27.57)$ & 55.9 \\
\hline 5 & Thana para (residential area) & 95 & 57.1 & 103.3 & $82.74( \pm 32.66)$ & 56.5 \\
\hline 6 & Mahmudul Hasan college (sensitive area) & 93 & 57.7 & 104.6 & $80.63( \pm 33.16)$ & 53.3 \\
\hline 7 & Babi stand (commercial area) & 83 & 66.5 & 112.3 & $86.69( \pm 32.39)$ & 78.9 \\
\hline
\end{tabular}

All the measurements were taken at three different times during day time (between 11 am to $1 \mathrm{pm}) ; * \mathrm{~N}=$ no. of observations.

Table 2. Traffic noise in TMA along the New bus stand

\begin{tabular}{|c|c|c|c|c|c|}
\hline \multirow[t]{2}{*}{ S. no. } & \multirow[t]{2}{*}{ Types of vehicle } & \multirow[t]{2}{*}{$\mathrm{N}$} & \multicolumn{2}{|c|}{ Sound pressure levels, $\mathrm{dB}(\mathrm{A})$} & \multirow[t]{2}{*}{$\operatorname{Average}(\mathrm{Sd} \pm)$} \\
\hline & & & Min & Max & \\
\hline 1 & $\begin{array}{l}\text { Normal condition (noise produced } \\
\text { other than vehicles) }\end{array}$ & 35 & 58.4 & 79.6 & $85.21( \pm 33.02)$ \\
\hline 2 & $\begin{array}{l}\text { Automobiles (Babi Taxi, Motorcycles, } \\
\text { CNG operated vehicles) }\end{array}$ & 40 & 73.8 & 99.2 & \\
\hline 3 & Medium bus and truck & 40 & 79.7 & 99.4 & \\
\hline 4 & Heavy bus and truck & 40 & 86.0 & 105.1 & \\
\hline
\end{tabular}

Table 3. Traffic noise in TMA along the Old bus stand

\begin{tabular}{|c|c|c|c|c|c|}
\hline \multirow[t]{2}{*}{ S. no. } & \multirow[t]{2}{*}{ Types of vehicle } & \multirow[t]{2}{*}{$\mathrm{N}$} & \multicolumn{2}{|c|}{ Sound pressure levels $\mathrm{dB}(\mathrm{A})$} & \multirow[t]{2}{*}{ Average $(\mathrm{Sd} \pm)$} \\
\hline & & & Min & $\operatorname{Max}$ & \\
\hline 1 & Normal condition & 34 & 57.6 & 86.8 & \\
\hline 2 & Automobiles & 35 & 81.2 & 100.3 & $87.71( \pm 33.79)$ \\
\hline 3 & Medium bus and truck & 30 & 71.9 & 103.9 & \\
\hline 4 & Heavy bus and truck & 25 & 84.4 & 105.4 & \\
\hline
\end{tabular}

Table 4. Standard noise levels in various areas

\begin{tabular}{|c|c|c|c|c|}
\hline \multirow[t]{2}{*}{ Description of areas } & \multicolumn{3}{|c|}{ Noise level dB(A) } & \multirow[t]{2}{*}{ Present results } \\
\hline & DoE* & $\mathrm{FHA}^{*}$ & AASHTO* & \\
\hline $\begin{array}{l}\text { Sensitive areas such as parks, } \\
\text { schools, hospitals and mosques }\end{array}$ & 45 & 60 & $55-60$ & 99.9-104.6 \\
\hline Residential areas & 50 & 70 (Interior max. 55) & 70 exterior - 55 Interior & 103.3 \\
\hline Mixed area & 60 & 70 & 70 & $105.1-105.4$ \\
\hline Commercial area & 70 & 75 & 75 & $101.3-112.3$ \\
\hline Industrial area & 75 & 75 & 75 & --- \\
\hline
\end{tabular}

${ }^{*} \mathrm{DoE}=$ Department of Environment, Bangladesh; *FHA = Federal Highway Agency; *AASHTO = American Association of State Highway and Transportation Officials. (Source: Ahmed, 1998; OECD, 1995). 
during the day time. The minimum and maximum noise level near the hospital road was 57.1 and $101 \mathrm{~dB}$ (A), respectively (Table 5).

The traffic noise measured at the spots along main road in Nirala Mur area, centre of TMA is shown in Table 6. Nirala Mur is highly constructed area which is commercial in nature and as such form the commercial hub of TMA. The minimum and maximum noise levels observed at the place were 62.3 and $101.3 \mathrm{~dB}(\mathrm{~A})$, respectively. The permissible level for mixed area is $60 \mathrm{~dB}(\mathrm{~A})$ (Bangladesh Standard, Table 4) and 70 decibels dB (A) (UK Standard, Table 10). Out of 87 trials at this location, the noise level has surpassed the permissible limit.
The minimum and maximum noise levels measured at the Mahmudul Hasan College were 57.7 and 104.6 dB (A), respectively. In this sensitive area, out of 93 trials, the average noise level was $80.63 \mathrm{~dB}$ (A) which surpassed the permissible limit $45 \mathrm{~dB}$ (A) for Bangladesh (Table 7).

The minimum and maximum noise levels measured at the Thana Para (residential) area were 57.1 and 101.2 $\mathrm{dB}(\mathrm{A})$, respectively. The permissible level for the residential area are $50 \mathrm{~dB}(\mathrm{~A})$ (Bangladesh DoE Standard, Table 4) and 70 decibels dB (A) (UK Standard, Table 10). Out of 95 trials at this location, the average noise level was $82.74 \mathrm{~dB}(\mathrm{~A})$ which surpassed the permissible limit (Table 8).

Table 5. Traffic noise in TMA along the hospital road

\begin{tabular}{llllll}
\hline \hline S.no. & Types of vehicle & N & \multicolumn{2}{l}{ Sound pressure levels dB(A) } & Average(Sd \pm ) \\
\cline { 4 - 5 } & & Min & Max & \\
\hline 1 & Normal condition & 34 & 57.1 & 78.1 & $84.07( \pm 30.34)$ \\
2 & Automobiles & 39 & 81.3 & 101 & \\
3 & Medium bus and truck & 36 & 80.2 & 97.7 & \\
4 & Heavy bus and truck & 26 & 82.2 & 99.9 & \\
\hline \hline
\end{tabular}

Table 6. Traffic noise in TMA along the Nirala Mur

\begin{tabular}{llllll}
\hline \hline S.no. & Types of vehicle & $\mathrm{N}$ & \multicolumn{2}{l}{ Sound pressure levels dB(A) } & Average( $\mathrm{Sd} \pm)$ \\
\cline { 3 - 5 } & & Min & 62.3 & Max & \\
\hline 1 & Normal condition & 31 & 71.6 & 85.0 & \\
2 & Automobiles & 35 & 80.5 & 101.3 & $81.68( \pm 27.57)$ \\
3 & Medium bus and truck & 21 & 95.6 & \\
\hline \hline
\end{tabular}

Table 7. Traffic noise in TMA along Mahmudul Hasan College

\begin{tabular}{llllll}
\hline \hline S. no. & Types of vehicle & $\mathrm{N}$ & \multicolumn{2}{l}{ Sound pressure levels dB(A) } & Average $(\operatorname{Sd} \pm)$ \\
\cline { 3 - 5 } & & Min & Max & \\
\hline 1 & Normal condition & 38 & 57.7 & 88.5 & \\
2 & Automobiles & 38 & 74.8 & 99 & $80.63( \pm 33.16)$ \\
3 & Medium bus and truck & 17 & 81.6 & 104.6 & \\
\hline \hline
\end{tabular}

Table 8. Traffic noise in TMA along the Thana Para

\begin{tabular}{llllll}
\hline \hline S. no. & Types of vehicle & N & \multicolumn{2}{c}{ Sound pressure levels dB(A) } & Average(Sd \pm$)$ \\
\cline { 4 - 5 } & & 31 & 57.1 & Max & \\
\hline 1 & Normal condition & 32 & 81.2 & 95.91 & \\
2 & Automobiles & 19 & 77 & 101.2 & $82.74( \pm 32.66)$ \\
3 & Medium bus and truck & 13 & 81.2 & 95.1 & \\
4 & Heavy bus and truck & & & 103.3 & \\
\hline \hline
\end{tabular}


Table 9. Traffic noise in TMA along the Baby stand road

\begin{tabular}{llllll}
\hline \hline S. no. Types of vehicle & \multirow{2}{*}{$\mathrm{N}$} & \multicolumn{2}{l}{ Sound pressure levels dB(A) } & Average $(\mathrm{Sd} \pm)$ \\
\cline { 3 - 5 } & & Min & Max & \\
\hline 1 & Normal condition & 25 & 66.5 & 91.3 & $86.69( \pm 32.39)$ \\
2 & Automobiles & 26 & 85.1 & 100.2 & \\
3 & Medium bus and truck & 19 & 85 & 103.4 & \\
4 & Heavy bus and truck & 13 & 86.5 & 112.3 & \\
\hline \hline
\end{tabular}

Table 10. Tolerated noise levels on the main roads for United Kingdom

\begin{tabular}{lll}
\hline \hline Type of noise & \multicolumn{2}{l}{ Tolerance limit, $\mathrm{dB}(\mathrm{A})$} \\
\cline { 2 - 3 } & Day & Night \\
\hline Basic noise level & 70 & 65 \\
Frequent peaks & 80 & 70 \\
Infrequent peaks & 90 & 80 \\
\hline \hline
\end{tabular}

Source: Murthy et al., 2007

\section{Conclusion}

Transportation operations are major contributors to create noise in modern urban areas. Here, noise is created by the engine, hydraulic horn, exhaust system of vehicles, interaction between the tyres and road system, and traffic jam. The departure from prescribed limit is substantial and with this level on a chronic measure of time can cause health problems to the exposed population. Most of the sensitive and important institutions, infrastructure and establishment are located along and near the roadside in TMA.

The findings suggest that institutions should take immediate regulatory measures to minimize and control high motoremanated environmental noise levels in most important areas in Tangail Municipal Area such as: hospital areas, college and school areas, residential areas, mixed, commercial and other areas. To prevent above mentioned disturbances and hearing loss due to noise, the findings of the study facilitate to create awareness among common public residing in the town. It is expected from the study, concerned authority will take proper steps to prevent the excessive level of noise and also to maintain peaceful environment for urban dwellers.

Following suggestions may be considered to control unwanted noise in TMA as: (i) control of automobile vehicles, such as Tempo inside the residential and sensitive areas, (ii) improvement of traffic system, (iii) to take necessary action to stop unnecessary use of horn, (iv) banning for hydraulic horns, (v) implement traffic rules and regulation, (vi) discouragement of high sound producing vehicles, (vii) planting of trees and construction of sound barriers on both sides of the road, (viii) improvement and streamlining of roads and parking system, (ix) increase public awareness and the role of NGOs, researchers and professionals, media and concerned individuals is involved in minimizing the environmental hazard of noise pollution.

It can be concluded that the suburban area (TMA) is environmentally noise polluted and road traffic are the major sources of it. Noting the noise emission standards, technical control measures, planning and promoting the citizens awareness about the high noise risk may help to relieve the noise problem, other wise it would be a serious environmental hazard.

\section{References}

Ahmed, K. 1998. A Study Noise Pollution in Dhaka City. Department of Environment (DoE), Bangladesh.

Alam, M.J.B., Rauf, A.F.M.A., Ahmed, M.F. 2001. Traffic induced noise pollution in Dhaka City. Journal of Civil Engineering, CE 29: 55-63.

BBS, 2001. Bangladesh Population Census; Community Series, Tangail District, Bangladesh, Bureau of Statistics, Dhaka, Bangladesh.

Kadiyali, L.R. 1997. Traffic Engineering and Transportation Planning. $6^{\text {th }}$ edition, Khanna Publishers, India.

Murthy, V.K., Majumder, A.K., Khanal, S.N., Subedi, D.P. 2007. Assessment of traffic noise pollution in Banepa, A semi urban town of Nepal. Kathmandu University Journal of Science, Engineering and Technology, 1: 1-9.

OECD, 1995. Roadside Noise Abatemant, Road Transport Research, Organization for Economic Cooperation and Development, Publication Services, OECD, France.

Papacostas, C.S., Prevedouros, P.D. 1993. Transportation Engineering and Planning. $2^{\text {nd }}$ edition, Prentice Hall Publishers, USA. 